\title{
Uso de regressão estatística para comparação de equipes de gestão de Facilities Management em unidades de uma mineradora
}

\author{
Wagner Jales (VALE S/A) wagner.jales@vale.com
}

\begin{abstract}
Resumo
O presente artigo buscou calibrar um modelo regressivo que permitisse estimar o efetivo de gestão/fiscalização de Facility Management em unidades industriais de uma grande mineradora. A pesquisa contou com dados coletados em 22 unidades desta mesma empresa. No final, o modelo calibrado não só permitiu fornecer uma métrica para equalizar a distribuição das pessoas entre as equipes, mas também compreender os diferentes graus de maturidade das unidades de negócio.
\end{abstract}

Palavras-Chaves: Dimensionamento de equipes, Facilities Management, Gestão, Regressão

\section{Introdução}

Segundo a definição do IFMA (International Facility Management Association) Facilities Management (ou FM) é a "gestão de facilidades é uma profissão que abarca múltiplas disciplinas, para assegurar a funcionalidade do ambiente construído, por meio da integração de pessoas, locais, processos e tecnologia”, e segundo o DIFM (Instituto Britânico de Gestão de Facilidades) é "a gestão de facilidades é a integração de atividades multidisciplinares dentro do ambiente construído e a gestão do seu impacto sobre as pessoas e o local de trabalho".

No Brasil, esses conceitos são associados à gestão condominial e envolvem atividades como manutenção predial, civil, elétrica, refrigeração, serviços de correspondências, limpeza predial, jardinagem e nos casos de condomínios industriais ainda se agregam ao conceito o transporte de empregados, TI e alimentação, chaveiro, dentre outros.

Esses serviços também existem em plantas industriais e é comum que as equipes que atuem nesse segmento se concentrem numa estrutura independente (e integrada) ao organograma das equipes que atuam na atividade-fim do negócio, dessa forma é possível dar foco e ter visibilidade do real esforço dessas atividades de suporte.

Para grandes empresas que possuem atuação em diferentes regiões, a busca por padronizar seus processos e, por consequência, suas equipes tem sido discussão constante. Os benefícios 
são refletidos em custos, seja pela simplificação de processos, seja pelo dimensionamento correto de suas equipes e é nesse segundo aspecto que se desenvolveu a presente pesquisa.

\section{AS TÉCNICAS PARA DIMENSIONAMENTO DE EQUIPES}

A partir da literatura pesquisada, é possível categorizar as técnicas para dimensionamento de equipes em três abordagens; a primeira com base no "mapeamento dos processos", a segunda, com base em índices de produtividade e a terceira, com base em benchmarking.

\subsection{Mapeamento de Processos}

Esse tipo de método pode as visto no trabalho de COELHO (2002) por exemplo onde o autor primeiramente modela "as cadeias de atividades dos processos correntes e ideais de uma empresa baseado na ferramenta IDEF Identification Definition" desenvolvida pela Força Aérea Americana onde o processo de financiamento de um bem ou serviço é subdivido em atividades (figura 1) e para cada atividade é estimado o tempo médio, multiplicando-se o volume total de demanda pelo tempo estimado de cada atividade, chega-se no tempo total para realização do processo e, consequentemente, no efetivo necessário para executara-la (Tabela 1).

Figura 1: Mapeamento de processo de vendas. Fonte: COELHO (2013)

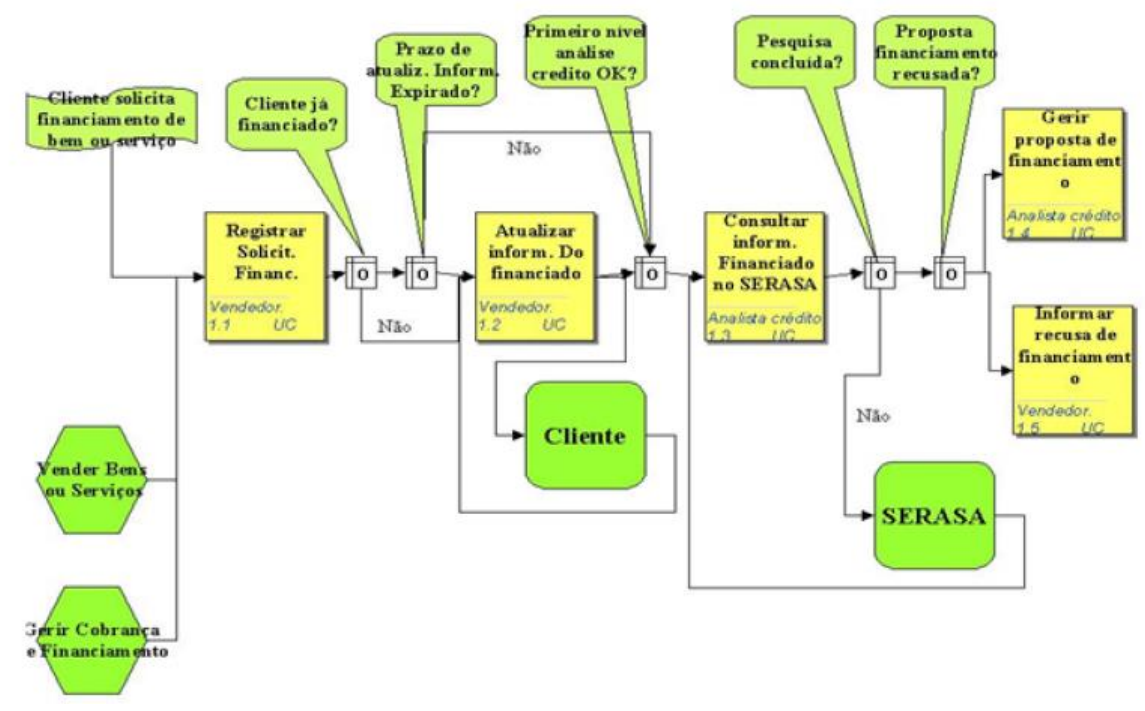

Tabela 1: Cálculo do tempo total (em minutos) para execução do volume de demanda das atividades. Fonte: COELHO (2013) 


\begin{tabular}{|l|l|l|l|}
\hline Atividade & Volume & TPU (tempo unitário) & TPT (tempo total) \\
\hline Registrar Solicit. Financ. & 12.000 & 3 & 36.000 \\
\hline Atual. Inform. Financiado & 7.800 & 6 & 46.800 \\
\hline Inform. Recusa Financ. & 3.600 & 10 & 36.000 \\
\hline Total & & & 118.800 \\
\hline
\end{tabular}

\section{2. Índices de produtividade}

É a abordagem a abordagem mais simples das 3 e tem seu emprego em diversos segmentos, na construção civil, saúde e telecomunicações. Basicamente consiste em predefinir coeficientes que relacionem a quantidade de mão-de-obra necessária para realizar determinada entrega. A origem dos parâmetros vem da observação do fenômeno em campo.

O SINAPI (Sistema Nacional de Pesquisas de Custos e Índices da Construção) adotado pelo banco CAIXA e a TCPO (Tabela de Composições e Preços para Orçamentos) desenvolvido e mantido pelo departamento de Engenharia da PINI. Os exemplos têm aplicação para orçamentos de Construção Civil, para cada tipo de serviço realizado ou "entregas" (pintura de parede, aplicação de cerâmica, etc...) se estabelece o tempo (HHT - Homem-Hora Trabalhada) dos profissionais necessários para realizar uma unidade da referida entrega (exemplo da tabela 2). Conhecendo o volume total dos serviços da obra, consegue-se chegar ao volume de mãode-obra total necessária realização da entrega.

Tabela 2: Composição de custos para execução de $1 \mathrm{~m}^{2}$ de "Emboço".

\begin{tabular}{l|c|c}
\multicolumn{3}{c}{ Adaptado do TCPO } \\
\hline Insumo & Unidade & Quantidade \\
\hline Pedreiro & $\mathrm{h}$ & 0,60 \\
\hline Servente & $\mathrm{h}$ & 0,80 \\
\hline Areia & $\mathrm{m}^{3}$ & 0,02 \\
\hline Cal hidratada & $\mathrm{kg}$ & 4,00 \\
\hline Cimento & $\mathrm{kg}$ & 2,40 \\
\hline
\end{tabular}

ARCE (2016) utiliza Pesquisa Operacional para otimizar a alocação das equipes de trabalho de Serviços Sociais, a partir dos parâmetros da NOB-RH (Norma Operacional Básica de Recursos Humanos) do Sistema Único de Assistência Social define um número mínimo de profissionais em função de um número de pessoas a serem atendidas, as "equipes constituídas por servidores efetivos responsáveis pela organização e oferta de serviços, programas, projetos e benefícios de proteção social básica e especial, levando-se em consideração o número de famílias e indivíduos referenciados, o tipo de atendimento e as aquisições que 
devem ser garantidas aos usuários (MDS, 2006)". Nesse documento se predefine a quantidade de profissionais por pessoas atendidas em um Abrigo Institucional (Tabela 3).

Tabela 3: Parâmetro que relaciona a quantidade de profissionais pela quantidade de acolhidos.

Fonte: ARCE (2016)

\begin{tabular}{|c|c|c|}
\hline Profíssional/Função & Escolaridade & Quantidade \\
\hline Coordenador & Nível superior ou médio & $\begin{array}{l}1 \text { profissional referenciado para } \\
\text { até } 20 \text { usuários acolhidos em, no } \\
\text { máximo, } 2 \text { equipamentos. }\end{array}$ \\
\hline Cuidador & $\begin{array}{lll}\text { Nivel } & \text { médio } & \text { e } \\
\text { qualificação especifica }\end{array}$ & $\begin{array}{l}\text { 1 profissional para até } 10 \\
\text { usuários, por turno. A } \\
\text { quantidade de cuidador por } \\
\text { usuário deverá ser aumentada } \\
\text { quando houver usuários que } \\
\text { demandem atenção específica } \\
\text { (com deficiência, com } \\
\text { necessidades especificas de } \\
\text { saúde, pessoas soropositivas, } \\
\text { idade inferior a um ano, pessoa } \\
\text { idosa com Grau de Dependência } \\
\text { II ou III, dentre outros). Para } \\
\text { tanto, deverá ser adotada a } \\
\text { seguinte relação: } \\
\text { a) } 1 \text { cuidador para cada } 8 \\
\text { usuários, quando houver } 1 \\
\text { usuário com demandas } \\
\text { especificas; }\end{array}$ \\
\hline
\end{tabular}

\subsection{Benchmarking}

Categorizou-se como de "Benchmarking" as técnicas que se baseiam na comparação de equipes sem entrar no detalhe das funções de cada profissional ou nos procedimentos para realização das entregas. É o caso o trabalho de MOREIRA, et al (2019) que, utilizando uma variação da Análise Envoltória dos Dados (DEA, do inglês Data Envelopment Analysis). redistribuiu todo o quadro de empregados que atendem às 80 estações ferroviárias da malha eletrificada do Rio de Janeiro.

DEA, como explica o próprio autor "são ferramentas utilizadas para análise de eficiência das DMUs (Decision Making Units ou Unidades Tomadoras de Decisão) por meio de uma abordagem não paramétrica baseada em modelos de programação linear comparando as quantidades produzidas, chamadas de outputs [entregas], em relação aos recursos utilizados ou inputs [mão-de-obra]”.

Sem entrar nos detalhes do modelo, a solução a) compara as entregas das diferentes estações (número de linhas atendidas, a movimentação de trens, média de passageiros e média máxima 
de passageiros em horários), b) identifica qual estação entrega mais com menos efetivo, c) recalcula o efetivo (mais eficiente, daí o termo "benchmarking") das demais estações com base na estação mais eficiente e; d) redistribui o efetivo excedente proporcionalmente para todas as estações, reequilibrando o efetivo.

A primeira técnica é a mais completa e precisa, parte da análise de cada entrega através do mapeamento do processo e o efetivo é dimensionado "na medida", é a mais complexa de se realizar pois exige grande esforço para se compreender todos os passos das entregas. $\mathrm{O}$ segundo conjunto de técnicas é útil para entregas que não sofrem grande dispersão amostral quanto ao tempo de realização delas (no caso da construção civil) ou quando a entrega não é algo tangível ou parametrizável (no caso, dos serviços de assistência social).

O terceiro conjunto de técnicas exige menos levantamento de dados que a primeira pois sua modelagem é agregada e absorve toda a complexidade dos processos envolvidos para realização das entregas. O que torna válido teoricamente é premissa de que todas as unidades de negócio comparadas (DMU's) realizam as mesmas entregas portando, deveriam consumir os mesmos recursos e possuir o mesmo efetivo.

O presente trabalho está categorizado na terceira técnica, mas ao invés de utilizar Pesquisa Operacional em sua modelagem, utilizou-se de Estatística e Regressão Múltipla.

\section{MATERIAIS E MÉTODO}

A pesquisa utilizou os dados de 22 equipes de FM (Facilities Management) de uma multinacional do ramo da mineração onde calibrou-se modelos regressivos considerando os dados operacionais como: área da unidade $\left(\mathrm{m}^{2}\right)$ onde a equipa atua, número de refeições produzidas, pessoas transportadas e empregados das unidades como variáveis independentes e os tempos (HHT - homem hora trabalhada) como variável dependente.

As primeiras foram aferidas considerando a média mensal de um período de 6 meses e os segunda, o que foi informado por cada empregado alocado nas 22 equipes. 
O passo-a-passo do método consistiu em: a) Análise descritiva dos dados de cada variável considerada no estudo; b) calculou-se as correlações (" $r$ " de Person) entre as variáveis independentes e a dependente; c) Calibração de modelos regressivos com múltiplas variáveis independentes e com apenas uma variável independente d) Validação do modelo que apresentou melhor resultado e; e) Análise dos resultados.

\subsection{Levantamento de dados em campo e análise descritiva}

Foram levantados em cada uma das 22 unidades, os tempos (em minutos) da equipe de FM. Foram apontados também volumes de dados das variáveis que representam os subprocessos como: a) Quantidade de Pessoas que trabalham no site; b) No. de Refeições produzidas por mês nos restaurantes do site; c) Área total do site $\mathrm{em} \mathrm{m}^{2} \mathrm{e}$ d) Pessoas Transportadas Empresa, Residência/Empresa Foram feitos histogramas das variáveis coletadas (Figuras 2a, 2b, 2c, 2d, 2e) para caracterizá-las.

Figura 2a: Histograma do Tempo da equipe de Gestão de FM.

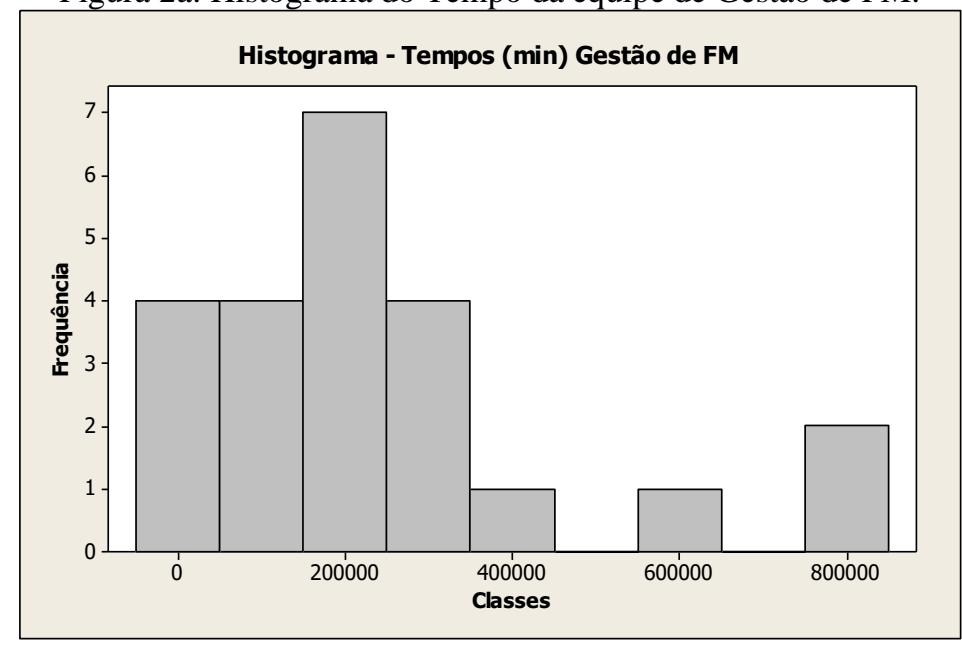

Figura 2b: Pessoas do site

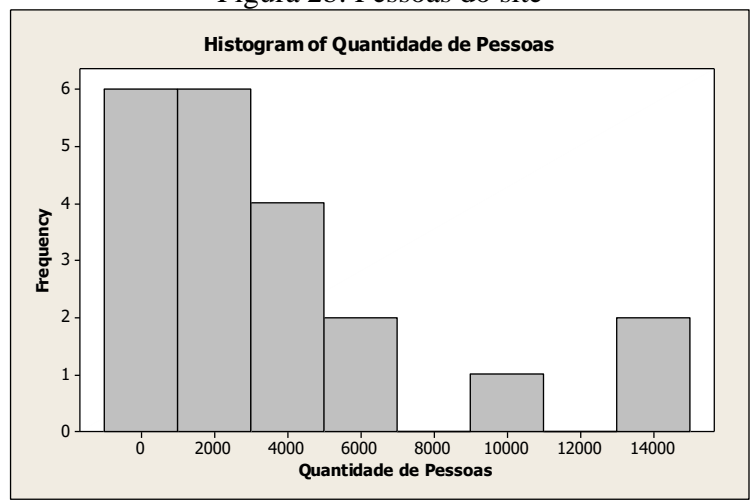

Figura 2c: No. de Refeições

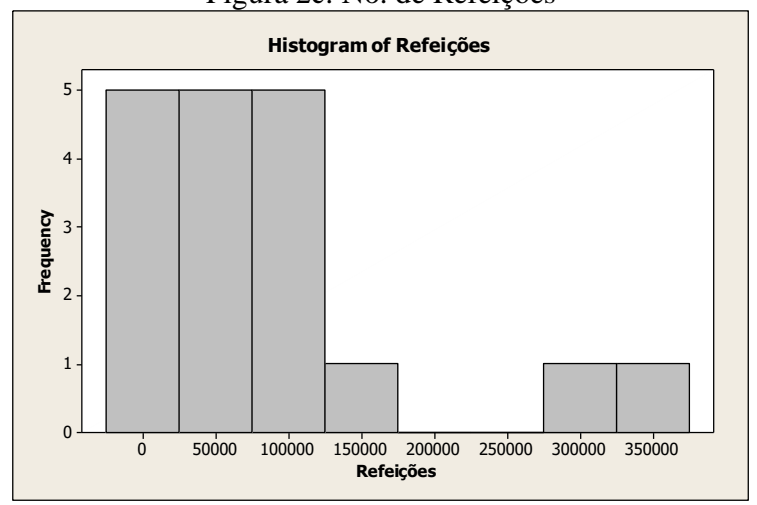


Figura 2d: Área do Site

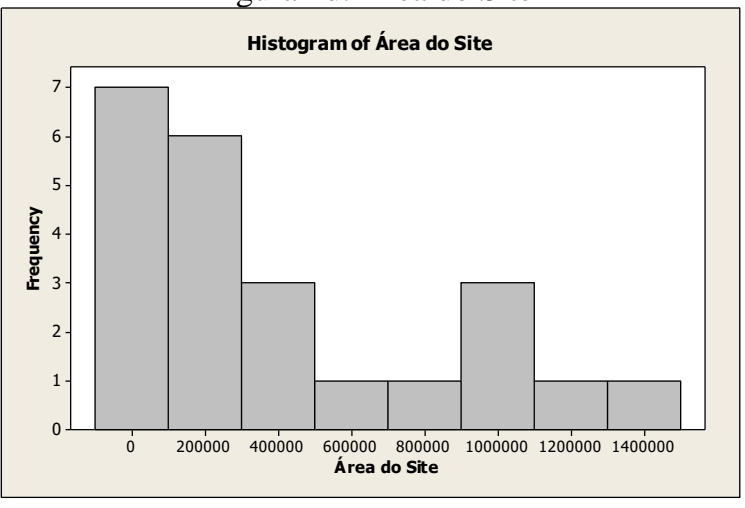

Figura 2e: Passageiros Transportados

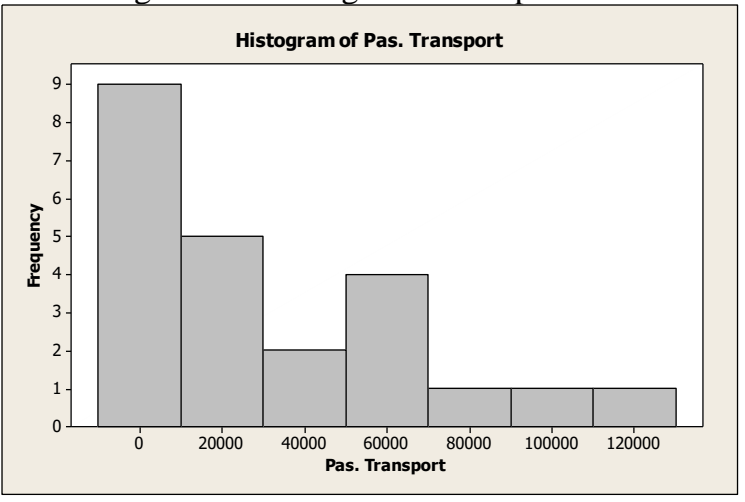

Apesar de não se proceder com nenhum teste para inferir qual a distribuição de frequência dos dados, as figuras 2a a 2e sugerem pelo menos 2 grupos de portes diferentes; a maioria de pequeno e médio porte (representado na alta frequência de classes de valores menores) e algumas unidades de grande porte (alguns dados concentrados em classes de valores maiores).

Em seguida, calculou-se as medidas de dispersão e tendência central das variáveis envolvidas (Tabela 2) e ao comparar a relação desvio padrão/média, a variável independente "área" tem a menor dispersão dos dados, maior apenas da variável dependente "tempo" em minutos.

Tabela 2: Medidas de dispersão e tendência central das variáveis levantadas

\begin{tabular}{lrrrrr}
\hline \multirow{2}{*}{ Medida } & \multicolumn{5}{c}{ Variável } \\
& \multicolumn{1}{c}{ Tempo (min) } & \multicolumn{1}{c}{ Pessoas } & \multicolumn{1}{c}{ Refeições } & \multicolumn{1}{c}{ Área $(\mathrm{m} 2)$} & Pas. Transp. \\
\hline Máximo & $828.612,40$ & $14.800,00$ & $361.700,00$ & $1.449 .937,75$ & $122.665,91$ \\
Mínimo & $12.950,00$ & 140,00 & $4.060,00$ & $9.335,17$ & 290,00 \\
Média & $242.883,75$ & $3.755,33$ & $86.084,73$ & $420.132,14$ & $32.591,71$ \\
Des vio & $217.212,84$ & $4.286,56$ & $102.048,52$ & $410.440,76$ & $33.595,51$ \\
Des vio/média & $89 \%$ & $114 \%$ & $119 \%$ & $98 \%$ & $103 \%$ \\
\hline
\end{tabular}

\subsection{Comparação das variáveis}

Para avaliar as relações entre as variáveis e identificar quais delas possui melhor relação linear com a variável dependente, procedeu-se o cálculo do "coeficiente de correção" ( $\mathrm{r}$ de Pearson, ver DEVORE, 2006) entre todas as variáveis. Tal coeficiente varia de "1" a "-1" e mede a relação linear entre 2 conjuntos de dados, quanto mais próximo de 1, maior a relação direta e quanto mais próximo de -1 , maior a relação inversa. 
Observou-se que a variável explicativa de maior correlação com a variável dependente é a variável independente "Área". Outra constatação esperada é a alta correlação entre "Refeições Produzidas" e "Passageiros Transportados" e "Pessoas do Site" e "Refeições Produzidas". (Tabela 3).

Tabela 3: Coeficiente de Correlação ("r" de Pearson) entre variáveis coletadas

\begin{tabular}{l|rrrr}
\hline & FTE & \multicolumn{4}{|c}{ Pessoas } & Refeições & Área total \\
\hline FTE & \multicolumn{6}{c}{} & & & \\
Pessoas & 0,771 & & & \\
Refeições & 0,727 & 0,817 & & \\
Área total & 0,8 & 0,797 & 0,777 & \\
Pas. Transp. & 0,741 & 0,722 & 0,888 & 0,769 \\
\hline
\end{tabular}

\subsection{Regressão Linear Simples e Múltipla}

Para iniciar o processo de calibração de um modelo, testou-se regressão simples de cada variável independente (Pessoas do site, No. de refeições, Área do site e Pessoas transportadas) contra a variável dependente - FTE de Gestão de FM. Usando o MINITAB ${ }^{\circledR}$ obtiveram-se os seguintes resultados (Tabela 4).

Tabela 4: Análise de Regressão Simples para as variáveis explicativas

\begin{tabular}{lllll}
\hline Variável Explicativa (x) & \multicolumn{1}{c}{ Equação } & S & $\mathbf{R}^{\mathbf{2}}$ & $\mathbf{R}^{\mathbf{2}}$ Ajust \\
\hline Pessoas do Site & $\mathrm{y}=101.380+33,70 * \mathrm{x}$ & 136707 & $59,40 \%$ & $56,50 \%$ \\
No. de Refeições & $\mathrm{y}=116.659+1,41 * \mathrm{x}$ & 147399 & $52,80 \%$ & $49,40 \%$ \\
Área total do site & $\mathrm{y}=29.415+0,456 * \mathrm{x}$ & 128706 & $64,00 \%$ & $61,40 \%$ \\
Pessoas Transportadas & $\mathrm{y}=62.153+4,30 * \mathrm{x}$ & 144031 & $54,90 \%$ & $51,70 \%$ \\
\hline
\end{tabular}

Os resultados encontrados não sugerem um modelo bem calibrado, o $\mathrm{R}^{2}$ (coeficiente de determinação) e o $\mathrm{R}^{2}$ ajustado conseguidos são medianos, procedeu-se o teste com regressão múltipla, combinando as variáveis explicativas duas a duas (tabela 5) e os resultados de $\mathrm{R}^{2}$ continuaram a abaixo de $70 \%$.

Tabela 5: Resultado do $\mathrm{R}^{2}$ ao se calibrar modelos de regressão múltipla combinando 2 variáveis

\begin{tabular}{l|rrr}
\hline & Pessoas do Site & No. de Refeições & Área total do site \\
\hline Pessoas do Site & & & \\
No. de Refeições & $62,2 \%$ & & \\
Área total do site & $68,9 \%$ & $66,8 \%$ & \\
Pessoas Transportadas & $66,5 \%$ & $57,1 \%$ & $67,9 \%$ \\
\hline
\end{tabular}




\subsection{Regressão Polinomial}

Considerou-se a possiblidade da relação entre variáveis não seja linear, então, a partir dos gráficos de dispersão das variáveis explicativas (x) e da variável explicada (y) gerou-se um modelo polinomial para a variável com maior com relação, no caso, Área do Site. O modelo polinomial gerado a partir da área do site gerou $\mathrm{R}^{2}$ maior conforme figura $3 . \mathrm{O} R^{2}$ ajustado encontrado foi $82,9 \%$, significativamente superior aos resultados encontrados nos modelos lineares.

Figura 3: Plotagem da Curva do Modelo Polinomial

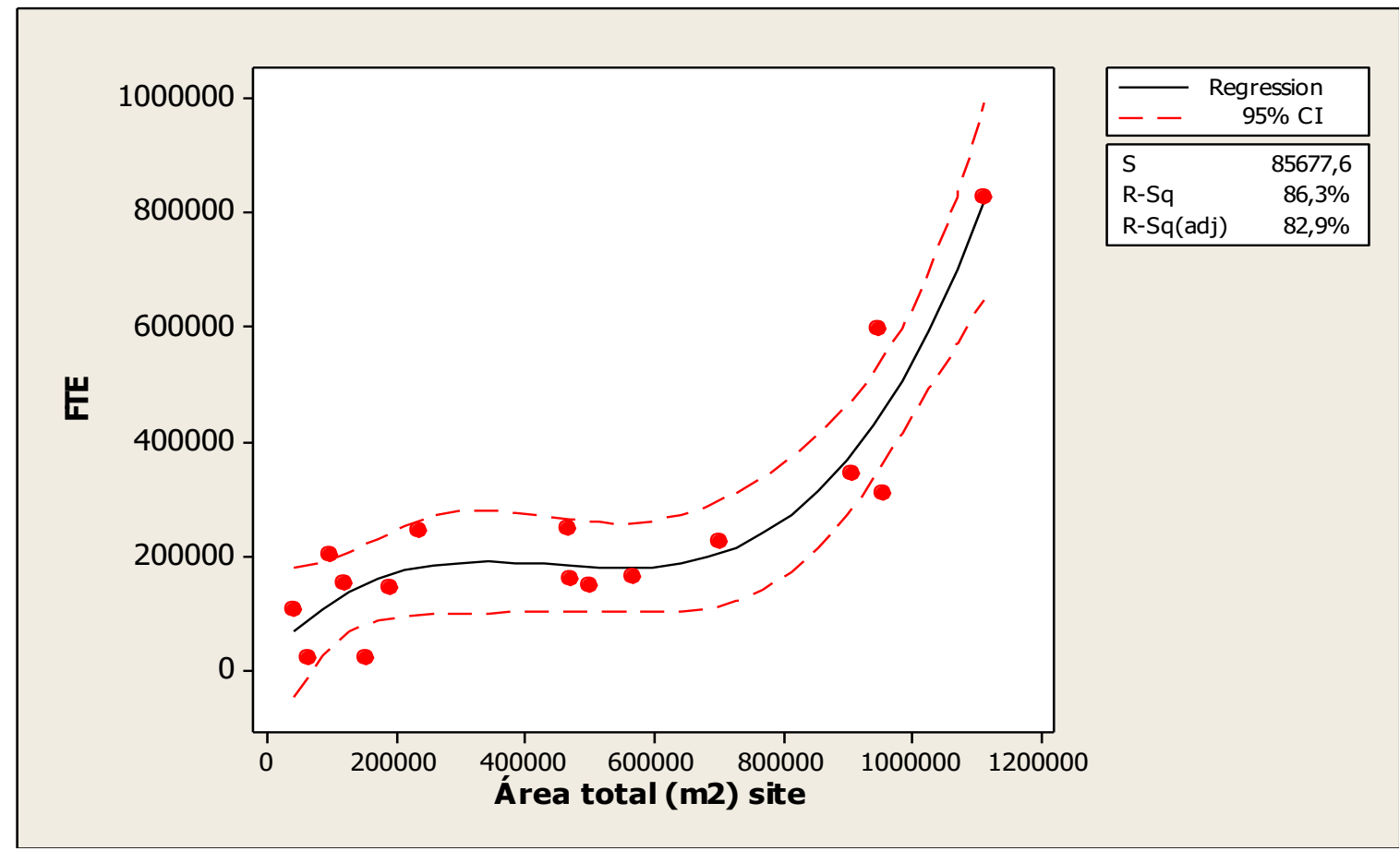

A equação encontrada foi a Equação 1:

$y=17637+1,274 * x-0,000003 * x^{2}+0,0000001 x^{3}$

(Equação 1)

\subsection{Validando o modelo}

Segundo TRIOLA (1998) um modelo para ser validado é preciso garantir a "Normalidade dos Resíduos", Homocedasticidade, a ausência de multicolinearidade e o teste de utilidade do modelo que consiste em testar a validade do coeficiente angular. O resíduo é o resultado da diferença dos valores esperados (dado pela equação encontrada) e os valores observados na 
amostra. Para o presente trabalho foi demonstrado apenas o teste de Normalidade dos resíduos (Figura 4)

Figura 4: teste de aderência à distribuição Normal dos resíduos

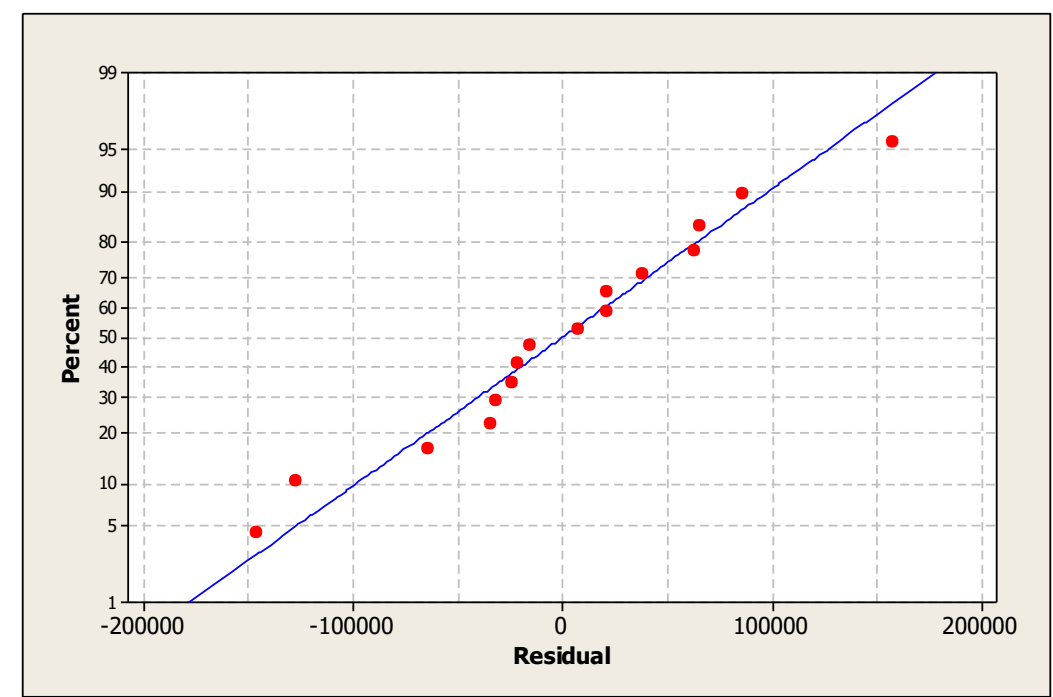

\section{DISCUSSÃO DOS RESULTADOS}

Tão útil quanto calibrar um modelo regressivo para estimar algum dado é conhecer um determinado fenômeno a partir da interpretação do modelo gerado, a partir da curva formada na figura 3 , é a identificação de estágios de maturidade das equipes onde, num primeiro momento, crescem proporcionalmente ao tamanho do site; num segundo estágio, as equipes se "estabilizam" e suportam crescimento da demanda (ganho de escala) mas, a partir de um determinado momento, as equipes voltam a crescer na proporção da demanda (Figura 5) 
Figura 5: Estágios de crescimento das equipes de gestão

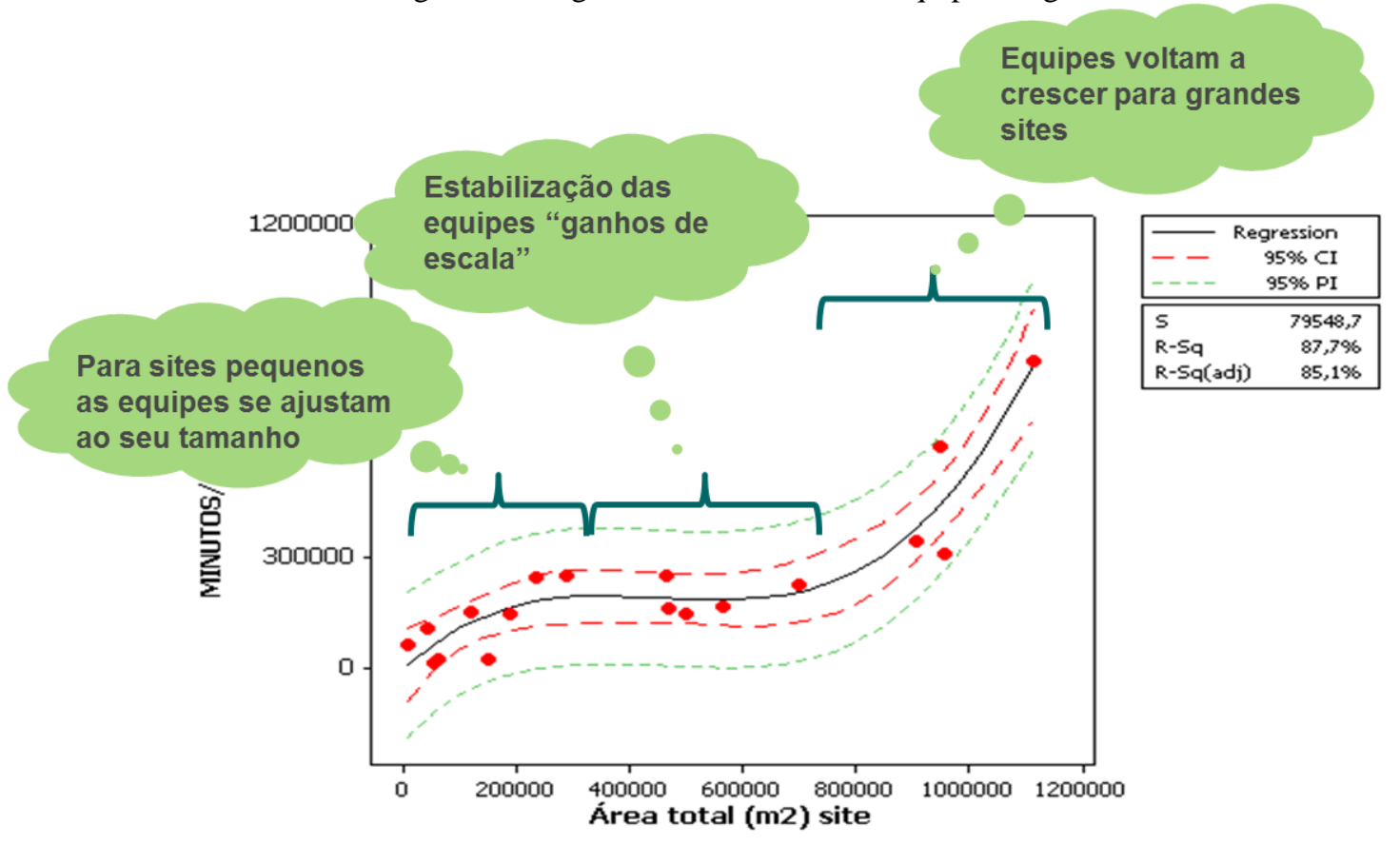

\section{CONCLUSÃO}

A distribuição dos subprocessos entre das equipes de FM vai da "generalização" a "especialização" profissional. Unidades menores tendem a generalização pois um profissional é responsável por mais de um subprocesso, mas, à medida que as demandas crescem e se tornam mais complexas exigindo mais controles, os subprocessos vão se tornando independentes exigindo que se tenham profissionais cada vez mais especializados (tabela 6). Como exercícios futuros, sugere-se a calibração de modelos que expliquem esse fenômeno da evolução das equipes.

Tabela 6: Esquema exemplificando a alocação de profissionais entre os subprocessos de FM para os 3 níveis de maturidade das equipes,

\begin{tabular}{|c|c|c|c|}
\hline \multirow{2}{*}{ SUBPROCESSO } & \multicolumn{3}{|c|}{ Estágios das Equipes } \\
\hline & 1 & 2 & 3 \\
\hline Manutenção Civil & \multirow{3}{*}{ A } & $A$ & A \\
\hline Manut Elétrica & & \multirow{2}{*}{ B } & $\mathrm{B}$ \\
\hline Climatização & & & $\mathrm{C}$ \\
\hline Transporte leve & \multirow{2}{*}{ B } & \multirow{2}{*}{$\mathrm{C}$} & $\mathrm{D}$ \\
\hline Transporte Coletivo & & & $E$ \\
\hline Limpeza predial & \multirow{4}{*}{ C } & \multirow{2}{*}{$\mathrm{D}$} & $\mathrm{F}$ \\
\hline Higienização de uniformes & & & G \\
\hline Manutenção de Jardins & & \multirow{2}{*}{$\mathrm{E}$} & $\mathrm{H}$ \\
\hline Correspondência & & & 1 \\
\hline
\end{tabular}


Como a variável "área do site" é também proporcional ao volume de produção da atividadefim da empresa (extração, transporte embarque do minério), é possível também que haja correlação entre indicadores operacionais e o dimensionamento das equipes de Facilities. Uma sugestão para pesquisas futuras é analisar as correlações entre indicadores operacionais e HHT das equipes de FM.

\section{REFERÊNCIAS}

ARCE, P. E. B. (2016), Otimização de processos em gestão de pessoas: aplicação de pesquisa operacional ao dimensionamento de equipes de trabalho de serviços da assistência social, Revista Eletrônica do CONBRAD Congresso Brasileiro de Administração. Volume 1, número 2. http://www.revistaconbrad.com.br/editorial/index.php/conbrad/article/view/127/32

Caixa Econômica Federal. SINAPI: Metodologias e Conceitos: Sistema Nacional de Pesquisa de Custos e Índices da Construção Civil / Caixa Econômica Federal. - 7ª Ed. - Brasília: CAIXA, 2019.

COELHO, M (2013), Gestão de pessoas: metodologia para dimensionamento de equipes, descrições de cargos e identificação de necessidades de treinamento. Revista Eletrônica Sistemas \& Gestão, Volume 8, Número 2, 2013, pp. 106-116, DOI: 10.7177/sg.2013.v8.n2.a9

DEVORE, J.L. (2006) Probabilidade e Estatística para Engenharia e Ciências. Ed. Pioneira Thomson Learning Ltda., São Paulo.

MINISTÉRIO DO DESENVOLVIMENTO SOCIAL (MDS). 2006. NOB-RH SUAS Norma Operacional Básica de Recursos Humanos do Sistema Único de Assistência Social.

http://www.mds.gov.br/assistenciasocial/publicacoes-para-impressao-em-grafica/norma-operacional-basica-derecursos-humanos-do-suas-nob-rh-suas

MOREIRA, L., MELLO, J. (2019). Aplicação de fronteira DEA parabólica para dimensionamento de equipes em estações ferroviárias do Rio de Janeiro. Simpósio Brasileiro de Pesquisa Operacional - SBPO. Limeira-SP. 2019.

TRIOLA, M. F. (1998) Introdução à Estatística. Editora LTC, $7^{\text {a }}$ Edição. Rio de Janeiro, RJ.

WEISE, A. D. (2011) Facility Management: contextualização e desenvolvimento, $11^{\text {a }}$ Conferência Internacional da LARES, São Paulo, SP.

TCPO. Tabelas de composições de preços para orçamentos. São Paulo: Pini, 2008. 